\title{
ESTÉTICA Y TEORÍA DE LA LITERATURA (NOTAS PARA UN ESTUDIO DE SUS RELACIONES SEGÚN LA TEORÍA EMPÍRICA DE LA LITERATURA DE S. J. SCHMIDT)
}

\author{
Antonio Chicharro Chamorro \\ Universidad de Granada \\ Mientras tanto, alzamos nuestra copa, \\ solemnes y atrevidos, \\ por la eterna salud de tu cadáver. \\ María Rosal Nadales \\ I
}

La elucidación de la posible relación que pueda guardar la teoría de la literatura actual con la disciplina estética resulta elementalmente necesaria a la hora de establecer con rigor los fundamentos en los que parece asentarse buena parte de las más ambiciosas teorías de la literatura actuales, teorías de corte literaturológico (en el sentido de Migno- 
lo). No en balde, Pedro Aullón (1994a: 105) ha dejado escrito que el siglo $\mathrm{XX}$ ha sido sustancialmente el de un acabamiento metafísico, el siglo neopositivista y formalista del estructuralismo y sus derivaciones en ciencias humanas, entre otras corrientes y vertientes paradigmáticas que podríamos ahora nombrar, por lo que se deduce sin dificultad alguna que son muchas las teorías que se han fundado sobre ciertos espacios disciplinares que ignoraban el solar de la estética. Por esta razón, me he ocupado de este problema capital en dos trabajos: uno, que abarca ciertos aspectos introductorios de proyección general, titulado «Estética y teoría y crítica literarias (Notas para un estudio de sus relaciones actuales)», de 1990, en el que dejé apuntado que, aunque la estética haya venido calando los estudios literarios a lo largo de los años, lo cierto es que en determinado momento de la historia del pensamiento literario de orientación científica se produjo un proceso de rechazo de la misma como espacio disciplinar básico donde asentar dicho pensamiento literaturológico. En este trabajo, por supuesto, no tuve más remedio que plantear el problema capital del valor literario, con objeto de ir deslindando responsabilidades disciplinarias, porque, de una parte, es éste el punto de apoyo básico de una labor propiamente crítico literaria, constituyendo la crítica literaria stricto sensu una disciplina que anda emparentada con la teoría literaria más por un dominio de ocupación que sirve de referencia que por una perspectiva básica compartida; $y$, de otra, el problema del valor es fundamental para la estética, ya se trate de una estética normativa que intente el establecimiento de las reglas del gusto o ya se trate de una estética que se ocupe de definir las condiciones formales de un juicio estético. Asimismo me ocupé de señalar algunas muestras significativas de la reacción que se vive en contra de la estética en tanto que marco teórico superior donde asentar una moderna teoría literaria. En concreto, hice referencia a algunas teorías literarias de base lingüístico-semiológica y a ciertas teorías de base marxista, concluyendo que existe hoy un espacio o marco teórico superior no específicamente estético donde vienen a confluir varias disciplinas. Se trata de la semiótica, espacio interdisciplinario materialista que se ocupa del estudio de la semiosis y, en ella, de la semiosis estética.

El otro breve estudio lo titulé «Estética y teoría de la literatura (Notas para un estudio de sus relaciones según Mijaíl Bajtín)» ${ }^{1}$. De su

1 Este trabajo, actualmente en prensa, fue leído como comunicación en el V Simposio Internacional de la Asociación Andaluza de Semiótica, celebrado en Almería, en diciembre de 1993. Algunas de sus conclusiones me fueron de preciosa utilidad para 
conveniencia apenas puede dudarse, si reparamos en la importancia y crédito teórico que ha alcanzado el pensamiento de Bajtín, el más ambicioso y complejo del pensamiento eslavo. Pues bien, creí conveniente tratar en aquella ocasión el problema básico planteado analizando teórico-críticamente el tratamiento que del mismo ha hecho el pensamiento eslavo en una, como digo, de sus más lúcidas formulaciones. Con sólo nombrar a los formalistas rusos, que negaron la estética como solar cognoscitivo donde asentar sus teorías para, a renglón seguido, sustentarlas en el paradigma de la moderna lingüística; y con sólo referirme al círculo de Bajtín que reaccionó en contra de los jóvenes teóricos del método formal criticando su cientificismo y su oposición a la (redefinida) estética general, podrá comprenderse la importancia que tiene el análisis de esta reacción ${ }^{2}$. Pues bien, centré mi análisis en las reflexiones contenidas en el trabajo de Bajtín «El problema del contenido, material y forma en la creación literaria» y más concretamente en la parte titulada "La ciencia del arte y la estética general», en la que rechaza el pensamiento estetizante por ser inconveniente para la teoría, así como rechaza entender el problema de la esencia del arte tanto en términos metafísicos como puramente lingüísticos, por sobrevalorar éstos el aspecto material de la creación artística, propugnando una estética de la creación verbal de orientación dialéctica y materialista, lo que ha contribuido de manera decisiva en el desarrollo de una disciplina que levanta su edificio teórico ni esencial ni estetizante sobre una base conceptual desvinculada de las prácticas estéticas, evitando toda confusión entre objeto real y objeto de conocimiento, distinguiendo entre conciencia cognoscente y conciencia estética etc., consciente de su propia historicidad y especificidad cognoscitiva.

dejar mínimamente establecido el «lugar» que ocupan ciertas teorías marxistas en el seno de los estudios estéticos y literarios en mi artículo «La teoría de la crítica sociológica» (Chicharro, 1994: 391-394).

2 No sólamente es interesante el estudio de las teorías de Bajtín y de su círculo sobre el particular, sino también, como resulta conocido, las del teórico checo Mukarovsky que abordó en los años treinta el problema de una estética semiológica habiendo recibido la influencia de los formalistas rusos. Véanse si no sus, en edición española, Arte y Semiología, con introducción de Simón Marchán Fiz (Madrid: Alberto Corazón, 1971), y Escritos de Estética y Semiótica del Arte, con prólogo de J. LLovet (Barcelona: Gustavo Gili, 1977). 


\section{II}

Efectuadas, pues, estas consideraciones introductorias voy a dar paso al tratamiento de este problema metateórico fundamental en el caso concreto de una de las teorías de la literatura actuales de más alta formalización teórica (Chico Rico, 1987 y 1991) con que contamos que, cabe adelantar, ha intentado desarrollar la conocida vía de separación disciplinar básica mediante la elaboración de una teoría de base pragmática, como es la del caso alemán de la teoría empírica de la literatura de S. J. Schmidt (1974; 1978, 1980; $c f$. para su bibliografía: Schmidt, 1980: 462-465; Albaladejo-Chico Rico, 1994: 289-290; e Iglesias, 1994: 354, para su bibliografía más reciente), una teoría que, por referirnos sólo al ámbito de nuestro país, ha recibido una cuantitativa y cualitativa diferente aceptación y tratamiento críticos, aunque bien es cierto que finalmente no ha pasado desapercibida (Chico Rico, 1987; Mayoral, ed., 1987; Pozuelo, 1988: 101-104; García Berrio, 1989: 196201, y 1994: 259-263, segunda edición; Chico Rico, 1991; Bobes Naves, 1994: 40-42; Chicharro, 1994: 443-445; Gnutzmann, 1994: 227-232; Iglesias Santos, 1994: 309-327; entre otros) e incluso ha posibilitado interesantes aplicaciones (Villanueva, 1992).

Pues bien, la teoría empírica de la literatura se presenta a sí misma como teoría (no participativa) ${ }^{3}$ global de la comunicación literaria, cuyo objeto no es otro que el estudio abstracto-formal (para su aplicabilidad) de la producción, mediación y recepción literarias, así como del «procesamiento» (cognitivo) de la literatura. Dicha teoría se basa en una perspectiva materialista de investigación, no limitándose al dominio de las «obras literarias», tal como son entendidas comúnmente, ni mucho menos a la literalidad de éstas. Ésta se ofrece, pues, como una teoría compleja que no considera aisladamente los hechos literarios, por lo que no separa sus facetas lingüístico-comunicativas de las sociales ni éstas de las estéticas. Para S. J. Schmidt, el contenido del concepto literatura sólo se llenará empíricamente, al no existir los textos literarios como entidad ontológica autónoma, con investigaciones

3 El principal fin de una teoría de este tipo es, según Schmidt (1980: 36), alcanzar la total separación entre la participación en la LITERATURA y la investigación científica en ella, pues sólo distinguiendo ambas actividades se podrá hallar solución a los problemas propios de la «didáctica de la literatura» y de la «crítica literaria» al rechazar así pretensiones científicas inviables o inadecuadas en ámbitos que tienen funciones sociales diferentes de las que se derivan de actividades científicas claramente definidas. Sobre esta importante cuestión ya se ocupó al dar entrada al punto de vista literariopsicológico a la hora de construir una teoría empírica de la literatura, utilizando para ello la Psicología de la literatura, de N. Groeben (cf. Schmidt, 1974: 59-61). 
sobre los procesos concretos de comunicación literaria. Así pues, esta teoría, basada en la pragmática como parte de la semiótica que trata de las relaciones entre los signos y sus usuarios, fundamenta su estudio en la descripción y explicación de las acciones sociales que se realizan alrededor de las obras de arte verbal y no en la pura literariedad de éstas, según la entendía el estructuralismo.

La teoría en cuestión parte de los conocidos siguientes supuestos (ibidem: 20-21): la existencia de un ámbito de acciones comunicativas que llamamos literatura; dicho ámbito puede ser descrito como un sistema social de acciones que posee una estructura, presenta una diferenciación exterior-interior, es aceptado por la sociedad y desempeña funciones que ningún otro sistema social de acciones asume; la estructura del sistema literatura está definida por cuatro papeles de actuación elementales - producción, mediación, recepción y transformación de comunicados literarios-, así como por las relaciones existentes entre ellos; dos convenciones son las que permiten la diferenciación exterior-interior del sistema literatura: la convención estética y la convención de polivalencia, convenciones cuya interpretación en la correspondiente situación socio-cultural por los participantes en la acción determina qué objetos deben ser valorados y tratados como objetos literarios (por lo que el concepto de literariedad sólo es definido histórico-pragmáticamente); la aceptación del sistema literatura por parte de la sociedad se manifiesta en la institucionalización de las relaciones con los comunicados literarios (por ejemplo, en la educación); y las funciones del sistema literatura atañen al mismo tiempo a los ámbitos cognitivo-reflexivo, moral-social y hedonista-individual de la actuación y de la vivencia.

Esta compleja teoría, que se inserta en la tradición alemana de la Literaturwissenchafst (Pozuelo Yvancos, 1988: 102), que se apoya modélicamente en la filosofía de la ciencia e incluso en ciertas teorías psicológicas ( $c f$. Schmidt, 1974: 59-65), lo que la diferencia de otras teorías del texto literario de base semiótica ${ }^{4}$, y que se basa, como hemos dicho, en la pragmática está creando las condiciones de explicación de

${ }^{4}$ Conviene señalar su proximidad teórica con la Teoría del Texto Literario de base lotmaniana, teoría que explica el hecho literario como lenguaje secundario. Pues bien, la relación y diferencia entre ambas teorías las ha señalado Mignolo con claridad metateórica en los siguientes términos (1986: 47-48): «Para J. Lotman, el texto artístico se organiza relacionando dos sistemas: uno el de la gramática; el segundo, el de otra estructura en la que confluyen varios sistemas culturales. S. Schmidt distingue el texto de la textualidad. El primero designa una entidad puramente lingüística, la segunda permite proponer la siguiente hipótesis: textualidad es la designación de un estructura bila- 
«lo que la gente ha hecho y sigue haciendo efectivamente cuando se relaciona con las obras literarias; por qué ha surgido la literatura en nuestra sociedad; cómo se ha desarrollado aquélla y qué función social ha desempeñado en el pasado y desempeña en el presente» (Schmidt, 1980 : 19).

La teoría empírica de la literatura pretende sacar la investigación científico-literaria de las llamadas ciencias del espíritu (Schmidt, 1980: 29) intentando poner fin a su larga crisis de fundamento y explicar así la acción social LITERATURA interdisciplinariamente (Schmidt, 1974: 66; 1980: passim; $c f$. Chicharro, 1994: 443-445). Por ello, se ocupa en principio de ofrecer una teoría de la acción -elemento teórico $1-$ y una teoría de las acciones comunicativas - elemento teórico 2-para desembocar en una teoría de las acciones comunicativas estéticas elemento 3-y, en particular, una teoría de las acciones comunicativas estéticas literarias -elemento 4-, en su producción -elemento 5-, mediación -elemento 6-, recepción -elemento 7- y transformación -elemento teórico 8.

Pues bien, para que exista una acción ha de haber un actante o agente que modifique/mantenga intencionalmente un estado en una situación determinada en el marco de su sistema de presuposiciones y de acuerdo con una estrategia. Cuando dicha acción se efectúa con ayuda de comunicados para un participante se producen acciones comunicativas.

Efectuada esta apretada síntesis introductoria, vamos a detenernos en lo que más nos interesa ahora, esto es, en conocer descriptivamente de momento en qué consisten para Schmidt las acciones comunicativas estéticas -este adjetivo lo emplea en el sentido de 'perteneciente al arte' y no en el más común de 'bello’o 'ameno', etc.- cuya definición y caracterización teóricas desempeñan la función de hacer explícitos los presupuestos generales que forman parte de la estructura de una teoría de las acciones comunicativas literarias (Schmidt, 1980: 124),

teral que puede ser considerada desde el punto de vista de los aspectos del lenguaje como desde el punto de vista social. Ambas versiones de la teoría del texto [Mignolo las unifica en esta denominación] pueden en algún momento acercarse, puesto que ambas contemplan la actividad comunicativa y el aspecto cultural involucrado en la noción de texto. La diferencia entre ambas es la acentuada tendencia hacia una ciencia empírico teórica (tomando como modelo la filosofía de la ciencia) en la segunda; y la base más propiamente semiológica de la primera». Por otra parte, no puede ignorarse que Schmidt dedica algunas páginas de sus Fundamentos de la ciencia empírica de la literatura (1980: 236-240) a ciertas teorías estructuralistas y en particular a las de Lotman con objeto de indicar la dirección en que deben abordarse las relaciones entre los elementos de la organización textual y el comportamiento del receptor. 
teniendo en cuenta para ello su exigencia de empiricidad y teoricidad, lo que lleva a este teórico a limitar su atención a los procesos de actuación comunicativa en el ámbito de actuación social «arte», no siempre existente en las distintas épocas históricas, frente a otros ámbitos de actuación social ${ }^{5}$, algo que ya había comenzado a tener claro en trabajos de los primeros años setenta y de lo que tiene plena conciencia en estudios como el titulado «La ciencia de la literatura entre la lingüística y la sociopsicología», de 1974 y traducido al español en 1978, en el que afirma:

\begin{abstract}
«Mi interés personal en el tratamiento de este tema lo expuse en una serie de trabajos (1970/1) donde traté de desarrollar algunos de los puntos de vista que a continuación se exponen, aunque algunos en forma distinta. Así p. e. el criterio de que el sector de investigación de una ciencia de la literatura no lo constituye (únicamente) el texto literario, sino la comunicación estética (y como una parte de ella la comunicación literaria)» (Schmidt, 1974: 41).
\end{abstract}

Pues bien, para Schmidt, un sistema de acciones comunicativas estéticas se caracteriza frente a los demás porque sus acciones comunicativas se refieren a aquellos comunicados temáticos o acciones que los participantes comunicativos consideran como estéticos en dicho sistema (Schmidt, 1980: 128). Una acción o comunicado es estético para un participante si éste los considera así sobre la base de las normas a las que recurre en una situación para esa valoración. El teórico alemán pretende solucionar de esta manera pragmática el problema de la definición del concepto de estético.

A continuación, propone estudiar este tipo de acciones dando cabida al tratamiento de la producción, mediación, recepción y transformación, su ámbito de investigación, formulando los criterios que delimitan el sistema de actuación «arte» frente a los demás sistemas: la convención estética y la convención de polivalencia. Mediante la primera, los participantes deben actuar de acuerdo con valores, normas y reglas de significación que son considerados como estéticos a partir de las normas asumidas en una situación dada. Esta convención ha tenido

5 Al principio de los años setenta, momento que corresponde todavía a la etapa de predominio de las teorías estructuralistas, Schmidt llegó a ocuparse del estudio de problemas como el de la naturaleza textual de la esteticidad y de otros aspectos del proceso estético (Schmidt, 1971a; 1971b; $c f$. a este respecto, García Berrio, 1994: 261), llegándose a traducir a nuestra lengua, por otra parte, su libro Teoría del texto (Problemas de una lingüística de la comunicación verbal), de 1973, una sistematizada aportación a la lingüística del texto (v. esp. Madrid, Cátedra, 1977; 1978, segunda edición). 
efectos sobre el productor y el receptor cuya descripción lleva a la conclusión de que en este sistema de acciones la situación o ámbito referencial del comunicado y el papel práctico que para el receptor puede jugar su enfrentamiento a la base del comunicado no están claramente definidos pudiendo haber sido determinados de muy diferentes maneras. En cuanto a los mediadores y transformadores, esta convención implica que aquéllos la acepten convirtiéndose en reguladores de actuación estética y los segundos que reciban como tal un comunicado estético (esta convención suprime, como expone Schmidt al teorizar particularmente sobre el sistema de la comunicación literaria, los criterios de verdad/falsedad y de utilidad/inutilidad presentes en los procesos comunicativos no literarios).

Mediante la convención de polivalencia - segundo criterio para delimitar el sistema de actuación «arte»- y mediante la crítica de la común comprensión ontológica de los comunicados y de sus bases en beneficio de una comprensión teórica de las propiedades de los comunicados como los resultados de las acciones de recepción, Schmidt (1980: 151) afirma que la polivalencia se refiere a la posibilidad valorada estéticamente de realizar una base de comunicado diacrónica y sincrónicamente como comunicado diferente y se refiere también al hecho de que un mismo receptor pueda realizar una base de comunicado diacrónicamente como comunicado diferente de una nueva manera coherente y relevante para él. Esto supone reconocer que los productores no se atienen a la univocidad en los comunicados y que los receptores tienen la libertad de producir resultados de recepción diferentes entre sí en distintos momentos y en situaciones de comunicación también distintas.

Ambas convenciones, formuladas aisladamente en el plano de la teoría, podrían mantener una relación fáctica en el sentido de que la convención estética establecería los presupuestos para la de polivalencia.

De todo lo expuesto teóricamente, Schmidt deduce la existencia real de un sistema de acciones comunicativas estéticas caracterizado por el hecho de que tales acciones giran en torno a comunicados estéticos en tanto que comunicados temáticos y caracterizado también por seguir las convenciones estética y de polivalencia y las regularidades de actuación propias de este sistema, sistema que posee una estuctura interior y un límite exterio-interior, es aceptado socialmente y desempeña funciones insustituibles, cumpliendo las funciones básicas, aisladas o relacionadas en concreto, cognitivo-reflexiva, moral-social y 
hedonista-individual, a las que al principio nos referíamos. Teorizadas las acciones comunicativas estéticas, se ocupa de ofrecer por extenso una teoría de las acciones comunicativas literarias, objeto de conocimiento nuclear de su teoría empírica de la literatura.

\section{III}

Efectuadas estas consideraciones preliminares y descripción de las explicaciones que esta teoría ofrece de lo que llama sistema de acciones comunicativas estéticas, estamos en condiciones de efectuar algunas reflexiones y precisiones al respecto.

En primer lugar, podemos decir sin temor a equivocarnos gravemente que la teoría empírica de la literatura que nos ocupa profundiza la separación observada a lo largo de, prácticamente, todo el siglo XX entre el pensamiento literaturológico y la disciplina filosófica estética. De manera que su estudio del dominio estético pertenecería más a lo que Rossi-Landi llamó, a propósito de Morris, de tan decisiva importancia para el desarrollo de la pragmática por cierto ${ }^{6}$, «semiótica estética» que a la «estética semiótica», pues la primera

«representa una especificación de la teoría o ciencia de los signos y por lo tanto permite aplicar al arte todo lo que la ciencia de los signos acoge en su propia constitución; mientras la segunda puede transmitir además la idea de una Estética y limitarse a calificarla precisando que esta vez se utilizarán también instrumentos semióticos. Dicho de otro modo, un semioticista estético se coloca, sin otra posibilidad, fuera de cierta tradición nuestra y no puede dejar de coger los avances de las ciencias del hombre, las cuales tienen todas que ver con la semiótica; por lo tanto le incumbe el trabajo de estudiar esos avances. En cambio el estetólogo semiótico puede ser tan sólo un hombre del pasado que intenta modernizarse adoptando extrínsecamente cierto lenguaje, y en tal caso ese lenguaje corre el riesgo de degradarse hasta el nivel de una mera jerga no dominada» (RossiLandi, 1972: 62-63).

6 No se olvide a su vez la deuda del pensamiento semiótico morrisiano con el de Peirce cuyas teorías han fecundado el actual desarrollo de los estudios pragmáticos, entre los que se cuentan los de la teoría que nos ocupa. En este sentido, el concepto nuclear de acción de la teoría empírica de la literatura halla su precedente en Peirce $c f$. por cierto el número monográfico de Signa dedicado a su estudio-, pues «el pragmatismo de Peirce - afirma A. Tordera (1978: 153) - ha encarnado la semiótica en una teoría de la acción, aunque insuficientemente elaborada, pero estableciendo, a pesar de ello, las bases de reflexión sobre las que la psicología y la sociología posteriores pueden implantar sus adquisiciones». 
Si tenemos en cuenta estos razonamientos, se comprenderá sin dificultad la razón que lleva a Rita Gnutzmann (1994) a criticar finalmente a esta teoría en los siguientes términos:

«Resulta obvio, si el camino recorrido en este ensayo muestra la paulatina autonomía y exaltación del valor estético-literario, con esta nueva corriente [la teoría empírica de la literatura] (y en general con la crítica sociológica) la literatura es nuevamente sometida a una relación de subordinación» (Gnutzmann, 1994: 232).

Así pues, después de su rápido recorrido por las grandes e influyentes sistematizaciones estéticas alemanas del pasado siglo, ciertamente importantes, y después de haber perseguido en su manual la «paulatina autonomía y exaltación del valor estético-literario», se comprende que la autora, al enfrentarse a la teoría literaria de buena parte del siglo XX, siglo de constitución de la misma «como ciencia autónoma, desgajada de la estética, en que vivió albergada» (Pozuelo, 1994: 70), haya optado por una vía cognoscitiva dejada de lado por el pensamiento literaturológico, sin comprender hasta sus últimas consecuencias la cuestión del lugar en que queda la literatura en este particular armazón teórico, lugar que no es de subordinación ni el mismo supone degradación alguna de esa práctica artística, sino que es el resultado de una radical separación cognoscitiva (no identificación con los entes literarios particulares, no confusión de dominio real y objeto de conocimiento y en definitiva, como expone Schmidt, no participación). La literatura, tal como comúnmente es entendida, no queda subordinada en el caso de la teoría que nos ocupa: la literatura o conjunto de textos literarios particulares queda fuera. El objeto de conocimiento son las acciones $o$, dicho con mayor exactitud, el sistema social de acciones LITERATURA a que nos hemos referido previamente y no los textos mismos, constituyendo ésta, precisamente, una de las razones que llevan a María del Carmen Bobes a dudar en un primer momento, desde su específica perspectiva semiótica, acerca de si la teoría empírica de la literatura es una ciencia literaria o una sociología de la literatura y a afirmar después que se trata de una teoría de la comunicación literaria que analiza la literatura por sus efectos sociales, una teoría que se basa en un concepto de literatura que desplaza el ser hacia el actuar (Bobes Naves, 1994: 40), posición teórica esta que viene a nutrir el nuevo horizonte postestructuralista que se instala en el seno de los estudios literarios y a alimentar la plural discusión acerca del problema nuclear de la objetividad textual de las propiedades estético-literarias vs. su carác- 
ter puramente convencional o pragmático, algo en lo que insistiremos más abajo. De ahí que haya quienes se refieran a esta teoría como una teoría sistémica, esto es, que se ocupa no de los textos sino, funcionalmente, del sistema social de acciones comunicativas ya referido (Iglesias, 1994: 311-312).

Pero es más, la teoría en cuestión no sólo profundiza en su radical alejamiento de la tradicional disciplina estética, sino que incluso pretende asentarse en unas bases cognoscitivas que le permitan situarse fuera del espacio propio de las diltheyanas ciencias del espíritu ( $c f$. Bobes Naves, 1994: 29-34), al plantear no sólo una dependencia con respecto a la filosofía de la ciencia en uno de sus desarrollos teóricos (cf. Mignolo, 1986; Chico Rico, 1987, entre otros), tal como lo expone Schmidt abiertamente,

«Las teorías analíticas de la ciencia han experimentado, en el curso de los últimos años, tan profundas transformaciones que no parece ya justificado en el momento presente dirigirles el reproche de neopositivismo. En otros términos, no existen argumentos sólidos por parte de la hermenéutica que puedan oponerse a la tentativa de edificar sobre la base de la variante de la teoría analítica de la ciencia desarrollada por W. Stegmuiller y J. D. Sneed, una ciencia de la literatura sistemática que pueda ser considerada como una alternativa a las variantes hermenéuticas» (Schmidt, 1978: 197),

sino también la necesidad de una «profundización» en el nivel biológico (cf. Chico Rico. 1991), por resultar no sólo productivo sino imprescindible para una teoría empírica de literatura a la hora de abordar el problema central de la comprensión. Así lo razona Schmidt:

«Si una teoría biológica de la cognición como la de G. Roth muestra plausiblemente que la percepción es un proceso constructivo y no un acto representador de «la realidad» y si del análisis de los procesos constructivos de percepción resulta que el «sentido» («Sinn») y el «significado» ( Bedeutung») tienen su origen en procesos auto-organizadores y autorreferenciales y que de esta forma, las ofertas de percepción - como, por ejemplo, los textos literarios- no pueden ser «tomadas», ello tiene para toda concepción científico-literaria importantes consecuencias» (Schmidt, 1980: 11).

Ahora bien, el hecho de que estas bases cognoscitivas sobre las que Schmidt construye o se propone construir su teoría - la filosofía de la ciencia de corte analítico y la teoría biológica de la cognición, entre otras ( $c f$. Schmidt, 1980: 27-28)- - supongan un máximo alejamiento de 
la estética, no quiere decir que realmente la conviertan en una teoría de orientación científica que llegue a abrir incluso un nuevo paradigma en los estudios literarios -el paradigma empírico-, tal como en algún momento llegó a plantearse, lo que ha sido estudiado con claridad metateórica por Montserrat Iglesias (1994: 311). De todos modos, no debemos dejar de reconocerle la importancia deíctica que tiene para las disciplinas que se ocupan del estudio de las prácticas históricas, sociales y artísticas esa voluntad de estudio riguroso inter e intradisciplinaria que pretende ir más allá de las tradicionales bases que sustentan las llamadas ciencias del espíritu.

En cualquier caso, lo que sí queda claro es que la aportación teórica que estudiamos potenció la crisis de las teorías inmanentistas y avivó la discusión sobre texto, literariedad y recepción al calor de estas bases, lo que ha llevado a García Berrio (1994: 260-263) a criticar a ésta y a otras teorías que han terminado por relativizar en extremo los fundamentos textuales de la literariedad como consecuencia de ese constructivismo cognitivo biologicista que pone al individuo en el origen de todo el proceso de construcción de la significación (Chico Rico, 1987; García Berrio, 1994: 261; Iglesias, 1994: 317). Por lo que a la teoría empírica de la literatura concierne, considera García Berrio que su tipo de investigación parece ajeno a los intereses de una teoría literaria; que el concepto de polivalencia niega en la práctica al texto la posibilidad de un núcleo de significado inequívoco ${ }^{7}$; que el concepto de convención estética afirma igualmente la inexistencia del significado artístico como valor inherente de los textos, entre otras críticas.

De esta manera, la teoría empírica de la literatura asiste a la fuerte discusión teórica actual sobre los anclajes textuales de la literatura, que ha tenido en el postestructuralismo derridiano implantado en Norteamérica, la desconstrucción, su movimiento más radical a la hora de poner en tela de juicio la «metafísica de la presencia», si bien desarrollando unas reflexiones en absoluto relativizadoras ni desacreditadoras, también al margen del horizonte de la metafísica, elaboradas en el evolucionado marco de una razón empírico-científica que le lleva a no reconocer la identidad textual literaria por sí misma, por lo que más

7 Téngase presente la distinción teórica que viene estableciendo García Berrio desde 1979 entre «literaridad» y «poeticidad», con objeto de reconocer, respectivamente, tanto los elementos textuales necesarios que fundamentan el fenómeno estético-literario como el valor cambiante de su recepción. El trabajo a que me refiero es el titulado «Lingüística, literaridad/poeticidad (Gramática, Pragmática, Texto)», 1616 Anuario de la Sociedad Española de Literatura General y Comparada, II, 1979, 125-168 (cf. Pozuelo, 1988: 76-77; Albaladejo-Chico Rico, 1994: 239-240). 
que prolongar y profundizar «el desaliento postestructuralista» (García Berrio, ibidem), representa el desarrollo, tan rígido y cientificista, eso sí, como articulado y coherente, de una pragmática de lo literario, una de las variadas respuestas posibles en el panorama teórico de este final de siglo.

En fin, con sus excesos sobre todo en cuanto a su aplicabilidad se refiere ( $c f$. Iglesias, 1994: 324) y sus limitaciones, la teoría empírica de la literatura ha avanzado en la dirección de movimiento no antiestética sino aestética que la investigación literaria inauguró en las primeras décadas del siglo que ahora termina. En este sentido, con las diferencias cognoscitivas lógicas, se hace deudora más del camino abierto por los formalistas rusos al respecto que del luego practicado por el círculo de Bajtín, cuyo concepto de "comprensión dialógica» y horizonte «translingüístico» suponen una fecunda opción cognoscitiva a la hora de explicar las prácticas o acciones estético-literarias.

\section{Referencias bibliográficas}

Albaladejo Mayordomo, T. y Chico Rico, F. (1994). «La teoría de la crítica lingüística y formal». En Teoría de la crítica literaria, P. Aullón de Haro (ed.), 175-293. Madrid: Trotta.

Aullón DE HARO, P. (1994a). «La construcción de la teoría crítico-literaria moderna en el marco del pensamiento estético moderno". En Teoría de la crítica literaria, P. Aullón de Haro (ed.), 27-113. Madrid: Trotta.

Aullón de HARO, P., ed. (1994b). Teoría de la crítica literaria. Madrid: Trotta.

BaJTín, M. (1975). Teoría y estética de la novela (Trabajos de investigación). Madrid: Taurus, 1989.

BOBES NAVES, M. C. (1994). «La literatura. La ciencia de la literatura. La crítica de la razón literaria». En Curso de teoría de la literatura, D. Villanueva (coord.), 19-45. Madrid: Taurus.

Chicharro Chamorro, A. (1990). «Estética y teoría y crítica literarias (Notas para un estudio de sus relaciones actuales)». En Teoría del Arte y Teoría de la Literatura, J. A. Hernández Guerrero (ed.), 105-117. Cádiz, Seminario de Teoría de la Literatura.

Chicharro Chamorro, A. (1994). «La teoría de la crítica sociológica». En Teoría de la crítica literaria, P. Aullón de Haro (ed.), 387-453. Madrid: Trotta.

Chicharro Chamorro, A.«Estética y teoría de la literatura (Notas para un estudio de sus relaciones según Mijanl Bajtín)». En prensa.

Chico Rico, F. (1987). «Fundamentos metateóricos de la Ciencia Empírica de la Literatura». Estudios de Lingüistica 4, 45-61.

Chico Rico, F. (1991). «La Ciencia Empírica de la Literatura en el marco actual de los estudios teórico-literarios». Periodística 4, 67-80. 
GARCÍA BERRIO, A. (1989). «La crisis postestructuralista: especialización pragmático-comunicativa de la Poética lingüística. La Teoría empírica de la literatura y el relativismo significativo de la recepción». En Teoría de la literatura (la construcción del significado poético), 196-202. Madrid: Cátedra. Segunda edición revisada y ampliada 1994, 259-263.

GnutzMann, R. (1994). «La ciencia empírica de la literatura». En Teoría de la literatura alemana, 227-232. Madrid: Síntesis.

IGLESIAS SANTOS, M. (1994). «El sistema literario: teoría empírica y teoría de los polisistemas». En Avances en teoría de la literatura (Estética de la recepción, pragmática, teoría empírica y teoría de los polisistemas), D. Villanueva (comp.), 309-356. Santiago de Compostela: Universidade.

MAYORAL, J. A., ed. (1987). Pragmática de la comunicación literaria. Madrid: Arco/Libros.

Mignolo, W. D. (1986). Teoría del texto e interpretación de textos. México: Universidad Nacional Autónoma de México.

Pozuelo Yvancos, J. Ma (1988). Teorías del lenguaje literario. Madrid: Cátedra.

Pozuelo Yvancos, J. Ma (1994). «La teoría literaria en el siglo XX». En Curso de teoría de la literatura, D. Villanueva (coord.), 69-98. Madrid: Taurus.

Rossi-LANDI, F. (1972). «Acerca del modo en que ha sido fragmentariamente comprendida la semiótica estética de Charles Morris». En Semiótica y Estética, 61-66. Buenos Aires: Nueva Visión, 1976.

SCHMIDT, S. J. (1971a). Ästhetizität. Philosophische Beiträge zu einer Theorie des Ästhetischen. München: Bayerischer Schulbuch-Verlag.

SCHMIDT, S. J. (1971b). Ästhetische Prozesse. Köln: Kiepenheuer \& Witsch.

SCHMIDT, S. J. (1974). «La ciencia de la literatura entre la lingüística y la sociopsicología (Algunos conceptos y problemas teórico-empíricos sobre una ciencia de la literatura)». Dispositio, III, 7-8, 1978, 39-70.

SCHMIDT, S. J. (1978). «La comunicación literaria». En Pragmática de la comunicación literaria, de J. A. Mayoral (ed.), 195-212. Madrid: Arco/Libros, 1987.

SCHMIDT, S. J. (1980). Fundamentos de la ciencia empírica de la literatura (El ámbito de actuación social LITERATURA). Madrid: Taurus, 1990.

TORDERA. A. (1978). Hacia una semiótica pragmática. Valencia: Fernando Torres.

VillanueVA, D. (1992). «Los marcos de la literatura española (1975-1990). Esbozo de un sistema». En Historia y crítica de la literatura española. IX Los nuevos nombres 1975-1990, 3-40. Barcelona: Crítica. 